\title{
Transesophageal Echocardiography in Anesthesiology: Characterization of Use Profile in a Tertiary Hospital
}

\author{
Alexander Alves da Silva, TSA ${ }^{1}$, Arthur Segurado, TSA ${ }^{1}$, Pedro Paulo Kimachi, TSA ${ }^{1}$, Enis Donizete Silva, TSA ${ }^{1}$, \\ Fernando Goehler, TSA ${ }^{1}$, Fabio Gregory, TSA ${ }^{1}$, Claudia Simões, TSA ${ }^{1}$
}

Summary: Silva AA, Segurado A, Kimachi PP, Silva ED, Goehler F, Gregory F, Simões C - Transesophageal Echocardiography in Anesthesiology: Characterization of Use Profile in a Tertiary Hospital.

Background and objective: Since its introduction in the 80s, transesophageal echocardiography (TEE) not only gained popularity but also experienced great advances in technology and currently it is an extremely valuable tool in the intraoperative period. In Brazil, there are no published data on the profile of its use in the intraoperative period by anesthesiologists. The objective of this study was to describe the use of intraoperative TEE in an Anesthesiology Service in a tertiary private hospital.

Patients and methods: Retrospective study from completed medical charts in all cases where the patient was monitored with TEE. Monitoring was applied in patients classified as I-II according to the American Society of Echocardiography and presenting no contraindication to the examination. At the end of procedure, after examination, a note on the chart classified monitoring according to its usefulness in the intraoperative period into three groups: group 1, no interference of TEE in anesthetic or surgical approach; group 2, TEE prompted change in anesthetic approach regarding the administration of volume, introduction and/or modification of vasoactive drugs (here, TEE generated change of anesthetic approach in conjunction with other monitors, but it was the deciding factor); group 3, TEE led to a change in approach or review of surgical procedure performed.

Results: From January 2009 to January 2011, 164 intraoperative TEE were performed in our service, with 41 pediatric and 123 adult patients. In all patients, the test was successful and there were no problems regarding the introduction of transesophageal tube. In pediatric sample, group I had 10 patients (24.4\%), group II had 27 patients (65.8\%), and group III had 4 patients (9.8\%). Among adults, group I had 38 patients (30.9\%), group II had 81 patients $(65.9 \%)$, and group III had 4 patients $(3.2 \%)$.

Conclusion: Despite this small sample size compared to the literature, and the limitations of this study, there was agreement with other reports related to changes in anesthetic-surgical approach based on intraoperative TEE. Our data also strongly suggest that transesophageal echocardiography is an extremely useful tool for monitoring patients at high cardiovascular risk, even when undergoing noncardiac surgery. Larger studies conducted in our country are needed, as there are no other studies in literature defining the use profile of TEE or even clearly setting out how it has been used in our field.

Keywords: Monitoring, Intraoperative; Echocardiography, Transesophageal; Anesthesia, General; Data Collection; Perioperative Period.

\section{INTRODUCTION}

Since its introduction in the 80 s, transesophageal echocardiography (TEE) has undergone great technological advances and gained popularity among anesthesiologists. Currently, it is an extremely valuable tool in the intraoperative period and widely used by various anesthesiology services in the USA and Europe ${ }^{1,2,3}$.

Received from Hospital Sírio Libanês, São Paulo, Brazil.

1. MD, Anesthesiologist, São Paulo Serviços Médicos de Anestesia.

Submitted on July 25, 2011.

Approved on January 19, 2012.

Correspondence to:

Alexander Alves da Silva, $M D$

$R$ Leoncio de Carvalho, 303 ap 62

04003010 - São Paulo, SP, Brazil.

E-mail: alexskin@terra.com.br
In cardiac surgery, especially in valvuloplasties, birth defect correction, and minimally invasive surgery, TEE has its use well established ${ }^{4,5}$. In noncardiac surgery, despite the growing interest, there are still some controversies in literature regarding its routine use 6,7 .

According to the type of patient or surgery, TEE can be classified as Class I, no proven benefit of its use; Class II, situations in which the TEE may be useful, but indications need further evidence; and Class III, no current indication for the use of TEE ${ }^{8}$. Box 1 shows a summary of the information according to each class.

Due to the scarcity of reports on the use of TEE in our field, we found interesting to publish our experience, though small, believing that this will encourage other services already using the method to publish their results. Thus, perhaps in a not too distant future, we can characterize the use profile of TEE in Brazil, understand our case series, and try to find any indication of deviations regarding those suggested by literature, helping to assess the impact of TEE use in qualitative terms and ratify or not its importance in our daily practice. 
Box 1 - Summary of Indications for TEE

\begin{tabular}{lll}
\hline Class I & Class II & Class III \\
\hline $\begin{array}{l}\text { Patients with } \\
\text { ventricular } \\
\text { instability }\end{array}$ & $\begin{array}{l}\text { Intraoperative } \\
\text { monitoring of cardiac } \\
\text { patiets }\end{array}$ & $\begin{array}{l}\text { Coronary anatomy } \\
\text { and anastomosis } \\
\text { patency }\end{array}$ \\
$\begin{array}{l}\text { Valvuloplasties } \\
\text { Valve replacement }\end{array}$ & $\begin{array}{l}\text { Patient with } \\
\text { uncomplicated } \\
\text { endocarditis }\end{array}$ \\
$\begin{array}{l}\text { Correction of } \\
\text { congenital heart } \\
\text { defects with CPB* }\end{array}$ & $\begin{array}{l}\text { Aneurysms of the } \\
\text { heart muscle }\end{array}$ & $\begin{array}{l}\text { Detection of emboli } \\
\text { in orthopedic surgery }\end{array}$ \\
$\begin{array}{l}\text { Hypertrophic } \\
\text { cardiomyopathy }\end{array}$ & Cardiac tumors & $\begin{array}{l}\text { Pleuropulmonary } \\
\text { diseases }\end{array}$ \\
$\begin{array}{l}\text { Endocarditis with } \\
\text { extension to valve } \\
\text { apparatus }\end{array}$ & $\begin{array}{l}\text { Intracardiac foreign } \\
\text { body }\end{array}$ & $\begin{array}{l}\text { Administration of } \\
\text { cardioplegia }\end{array}$ \\
$\begin{array}{l}\text { Aortic disease } \\
\text { with hemodynamic } \\
\text { instability }\end{array}$ & Heart Transplant \\
$\begin{array}{l}\text { Pericardial windows } \\
\text { Hetection of air }\end{array}$ & \\
\hline $\begin{array}{l}\text { during cardiotomy } \\
\text { Cardipulmary }\end{array}$ & \\
\hline
\end{tabular}

${ }^{*}$ Cardiopulmonary bypass.

The objective of this study was to describe the use of intraoperative TEE in an Anesthesiology Service in a tertiary private hospital. This retrospective study was conducted with data from medical charts that are completed in all cases of patient monitoring with TEE. In these charts, the patient's clinical data, indication for TEE, and what was found in the examination are recorded. Moreover, all still images and films are stored on digital media, which allows us to review the cases both for didactic purposes and to clarify questions that may arise.

The apparatus used in all cases was the Sonosite Maxx Micro® with transesophageal probe for adults, also used in the examination of pediatric patients weighing $15 \mathrm{~kg}$ or more, considered the minimum weigh compatible with the size of our probe. For all procedures, according to the Infection Control Committee, the probe was coated with a plastic cover suitable for this purpose as seen on Picture 1.

Monitoring with TEE was applied in all patients classified as I-II, according to Box 1 , and with no contraindications for the procedure. The contraindication criteria were patients who underwent recent gastric or esophageal surgery (less than six weeks), patients with coagulation disorders with active bleeding, esophageal stenosis, tumor involving the esophagus, Zenker's diverticulum, and those with previous history of radiotherapy or esophageal varices.

We define as patients at risk for myocardial ischemia or intraoperative hemodynamic instability those with one of the following conditions: previous myocardial infarction (MI), his-

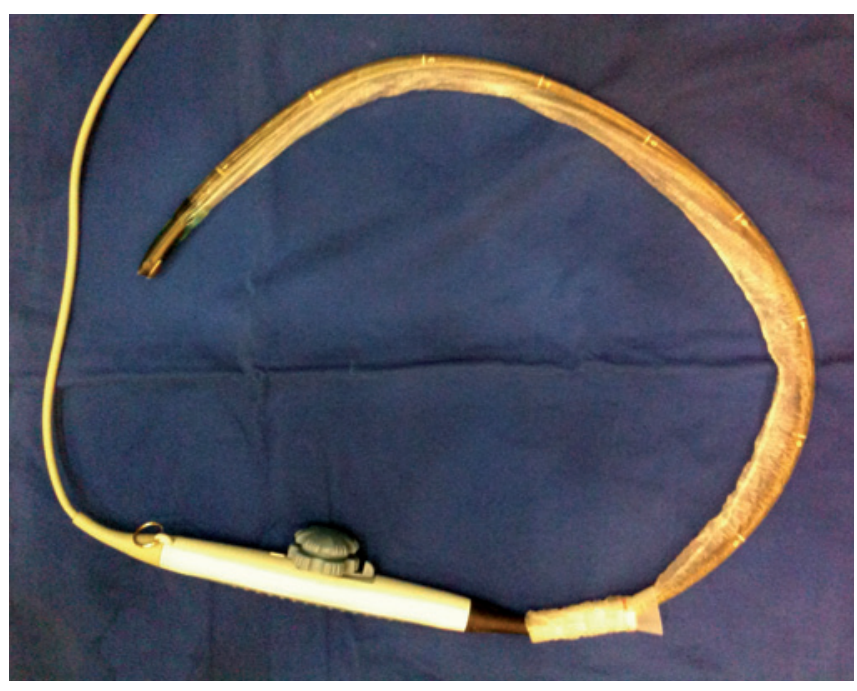

Picture 1 - Probe Plastic Cover.

tory of episodes of angina, myocardial scintigraphy or stress test positive, moderate or severe aortic stenosis, heart failure or pulmonary hypertension $(\mathrm{PH})$.

For TEE examination, we follow the American Society of Echocardiography and American Society of Cardiovascular Anesthesiologists guidelines. In all patients, a baseline examination was performed after induction of general anesthesia and tracheal intubation, and the following evaluations were performed:

1. Left ventricular end-diastolic area (LVEDA) in a transgastric transverse plane, considering the areas with values $>5.5 \mathrm{~cm}^{2} \cdot \mathrm{m}^{-2}$ and $<11.9 \mathrm{~cm}^{2} \cdot \mathrm{m}^{-2}$ as normal.

2. For analysis of segmental systolic function, we adopt the system suggested by the American Heart Association $(\mathrm{AHA})$ in conjunction with the Committees of the American Societies of Echocardiography, Cardiac Tomography, Cardiac Resonance, and Nuclear Medicine. According to the recommendation, the left ventricle is divided into 17 segments (Figure 1), to which a score is assigned according to contractility, being equal to 1 when the contractility is normal (thickening > 30\%); 2 when the segment is moderately hypokinetic (thickening between $10 \%$ and $30 \%$ ); 3 to severe hypokinesia (thickening $<10 \%$ ); 4 to akinesia; and 5 in case of dyskinesia. Worsening of a segment movement greater than or equal to a score of 2 on the scale and duration over 60 seconds was defined as a new episode suggestive of ischemia.

3. Color Doppler was used to evaluate blood flow through the aortic, mitral, tricuspid and pulmonary valves. Systolic pressure in pulmonary artery was assessed whenever tricuspid regurgitation was present, through the modified Bernoulli equation $\left(4 \mathrm{~V}^{2}+\mathrm{PVC}\right)$.

4. Cardiac output was calculated using the formula: $\mathrm{VTI}_{\mathrm{L}}$ voт $x$ LVOT Diameter $x$ HR. Where VTI LVOT is the velocity-time integral (VTI) of the route of left ventricular 

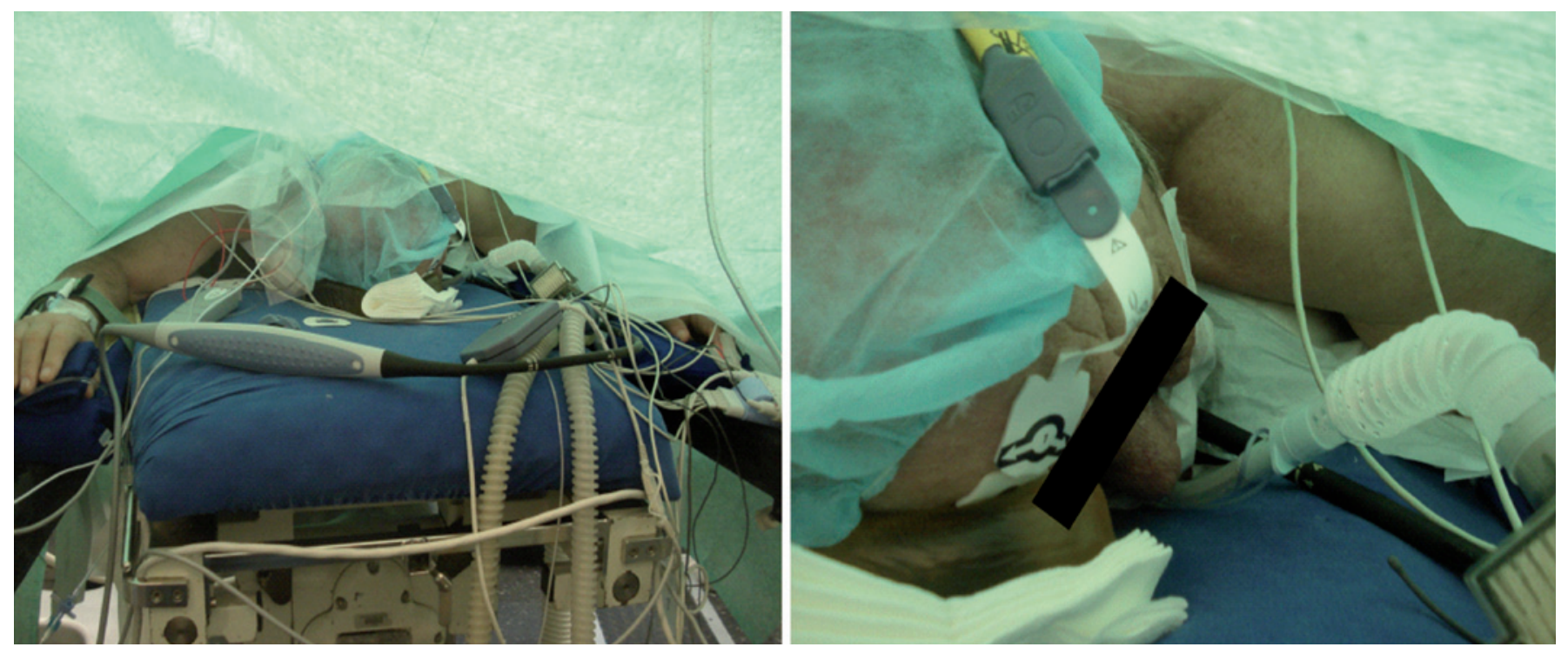

Picture 2 - Patient Undergoing Laminectomy and Lumbar Spine Fusion in the Prone Position, Monitored with TEE.

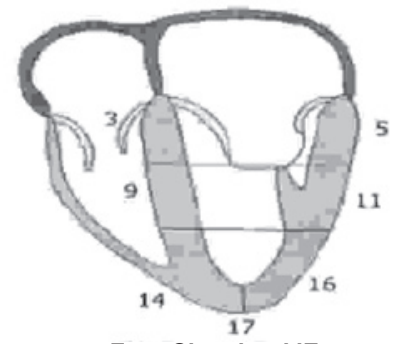

Four Chamber ME

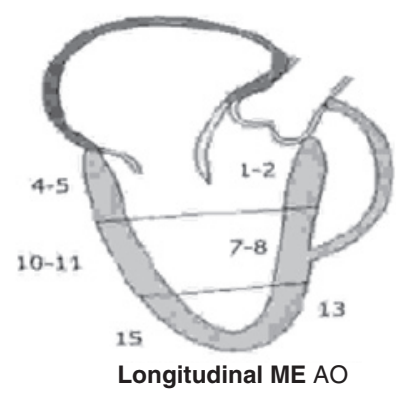

\begin{tabular}{|l|l|l|}
\hline Basal segments & Mid segments & Apical segments \\
1. Basal & 7. Mid anteroseptal & 13. Apical anterior \\
anteroseptal & 8. Mid anterior & 14. Apical lateral \\
2. Basal anterior & 9. Mid lateral & 15. Apical inferior \\
3. Basal lateral & 10. Mid posterior & 16. Apical septal \\
4. Basal posterior & 11. Mid inferior & 17. Apex LV \\
5. Basal inferior & 12. Mid septal & \\
6. Basal septal & & \\
\hline
\end{tabular}

Figure 1 - Model segmentation recommended by the American $\mathrm{He}$ art Association (AHA).

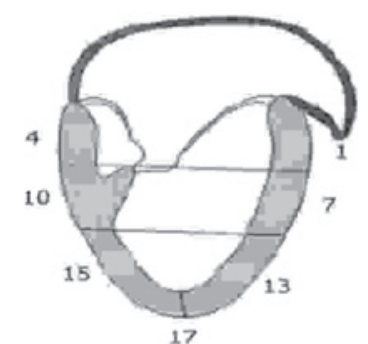

Two Chamber ME
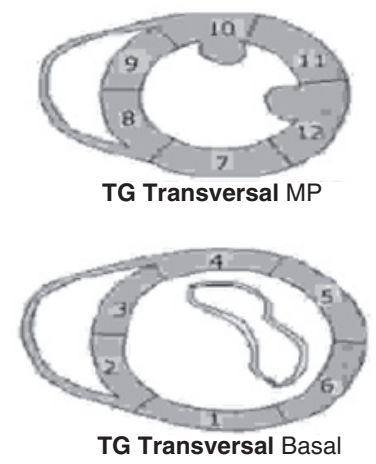

TG Transversal Basal

we use one of the following methods:

1. Respiratory variation of superior vena cava obtained through mid esophageal bicaval view evaluated by $\mathrm{M}$ mode, using the formula below and considering as responders those with Delta svc greater than $36 \%{ }^{9}$ :

Delta $_{\text {svc }}(\%)=\frac{\text { Maximal expiratory diameter }- \text { Minimum inspiratory diameter } \times 100}{\text { Maximum expiratory diameter }+ \text { Minimum inspiratory diameter }}$

2. Change in peak velocity of blood flow ejected by the left ventricle into the aorta during a respiratory cycle, applying the following formula and considering as responders those with Delta vpeak $_{\text {greater than } 12 \%}{ }^{10}$ : 
Delta $_{\text {Vpeak }}(\%)=100 \times($ Vpeakmax - Vpeakmin $) /[($ Vpeakmax+Vpeakmin $) / 2]$

After performing all measures, the transducer was left in the transgastric position showing the transverse plane at the level of papillary muscle to intermittent monitoring of contractility and ventricular volume. A new set of measurements was performed after the identification of ischemia or hemodynamic instability. In all cases, a final examination is performed before the patient leaves the operating room.

At the end of procedure, after examination, a note on the chart classified monitoring according to its usefulness in the intraoperative period into three groups: group 1, no interference of TEE in anesthetic or surgical approach; group 2, TEE prompted change in anesthetic approach regarding the administration of volume, introduction and/or modification of vasoactive drugs (here, TEE generated change of anesthetic approach in conjunction with other monitors, but it was the deciding factor); group 3, TEE led to a change in approach or review of surgical procedure performed.

\section{RESULTS}

From January 2009 to January 2011, 164 intraoperative TEE were performed in our service in 41 pediatric and 123 adult patients. In all patients, examination was successful and there were no problems regarding transesophageal probe insertion. Also, no serious complications arose from monitoring. Table I shows the demographic characteristics of patients included in the study.

All pediatric patients underwent cardiac surgery. Adult patients underwent conventional cardiac surgery $(n=28)$, percutaneous aortic valve replacement $(n=10)$, orthopedic surgery $(n=16)$, major abdominal surgeries $(n=66)$, vascular surgery via endovascular approach $(n=1)$, and neurosurgery in a seated position $(n=2)$. Table II shows the conditions found in children.

Table III shows the indications for monitoring and types of surgery performed in adults. Taking into account the indication according to each class, 37 patients were classified as Class I and 86 patients as Class II.

Table I - Demographic Characteristics of Patients

\begin{tabular}{lll}
\hline & Pediatric Patients & Adult Patients \\
\hline Sex & & \\
Female & 22 & 54 \\
Male & 19 & 69 \\
Age (years) & $8.29 \pm 4.41$ & $65.68 \pm 19.07^{*}$ \\
\hline
\end{tabular}

* Mean \pm standard deviation
Table IV shows the division of patients according to TEE usefulness on final classification. In pediatric group (Table IV), intraoperative TEE had no interference in the anesthetic or surgical approach in 10 cases, only serving as a monitor; and in 27 cases, it was useful in patient's hemodynamic management for adjustment or modification of blood volume and administration of vasoactive drugs. The incidence of second cardiopulmonary bypass (CPB) prompted by TEE was $7.3 \%$.

On four occasions, the use of TEE directly interfered in the surgical approach. First, a patient who underwent mitral valve repair has evolved with significant tricuspid insufficiency after weaned from CPB, having to return to CPB for proper correction (Figure 2). Second, a child who needed a residual atrial

Table II - Diseases Found in Children

\begin{tabular}{ll}
\hline ASD & 15 \\
Ostium secundum with $\mathrm{PH}^{1}$ & 8 \\
Ostium primum & 3 \\
Superior venous sinus & 2 \\
Superior venous sinus with ADPV ${ }^{2}$ & 2 \\
VSD & 12 \\
Tetralogy of Fallot & 4 \\
Isolated mitral cleft & 1 \\
Aortic coarctation $+\mathrm{SAH}^{3}$ & 1 \\
Tricuspid atresia & 2 \\
Mitral regurgitation & 3 \\
Aortic insufficiency & 3 \\
Total Children & 41
\end{tabular}

1: Pulmonary Hypertension; 2: Anomalous Drainage of Pulmonary Veins; 3 : Asymmetric Septal Hypertrophy.

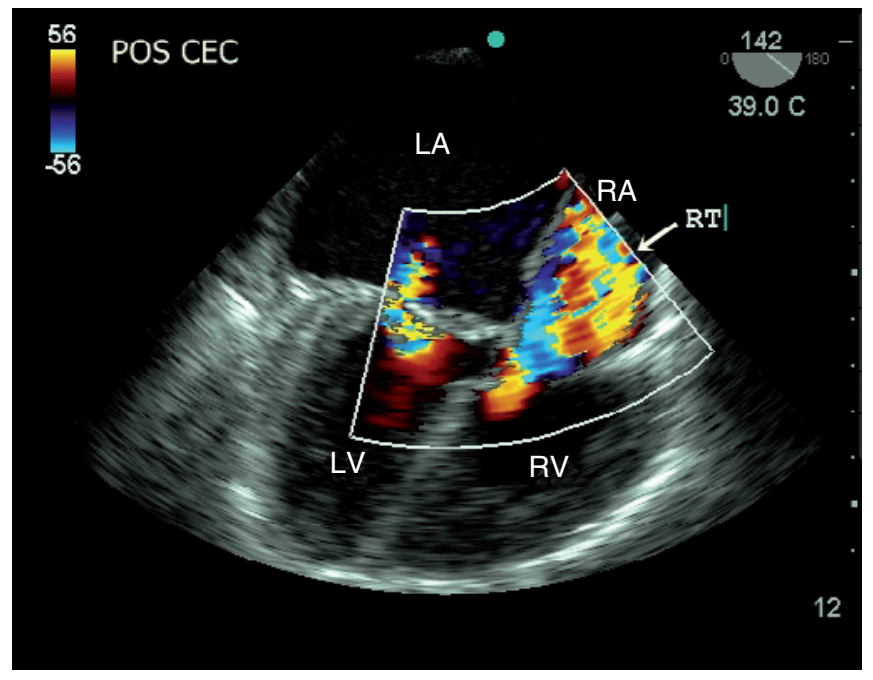

Figure 2 - Four Chamber Cut Inverted with Multiplane angle of $142^{\circ}$ Showing Right Chambers on the Right and Left Chambers on the Left of the Screen.

TR: tricuspid regurgitation; RA: right atrium, LA: left atrium, RV: right ventricle, LV: left ventricle. 
Table III - Indications for Monitoring and Types of Surgery Performed in Adults

\begin{tabular}{|c|c|c|c|}
\hline Indication & Patients (n) & Surgery & Class \\
\hline \multirow[t]{3}{*}{ Previous Ml } & 10 & Myocardial revascularization with CPB & I \\
\hline & 1 & Endovascular AAA $^{\text {a repair }}$ & II \\
\hline & 24 & Major abdominal surgery & II \\
\hline \multirow[t]{3}{*}{ History of Angina } & 10 & Total hip arthroplasty & II \\
\hline & 17 & Major abdominal surgery & II \\
\hline & 1 & Lumbar Laminectomy with Spinal Fusion & II \\
\hline \multirow[t]{3}{*}{ Scintigraphy or positive stress test } & 8 & Myocardial revascularization with CPB & I \\
\hline & 2 & Laparoscopic nephrectomy & II \\
\hline & 1 & Laparoscopic pancreatectomy & II \\
\hline \multirow[t]{3}{*}{ Moderate/severe aortic stenosis } & 1 & Aortic valve repair & I \\
\hline & 10 & Percutaneous aortic valve replacement & I \\
\hline & 1 & Conventional aortic valve replacement & II \\
\hline \multirow[t]{4}{*}{ Heart failure } & 17 & Major abdominal surgery & II \\
\hline & 3 & Total hip arthroplasty & II \\
\hline & 2 & Mitral valve repair & I \\
\hline & 2 & Mitral valve replacement & I \\
\hline \multirow[t]{5}{*}{ Pulmonary hypertension } & 1 & Hepatectomy & II \\
\hline & 1 & Total hip arthroplasty & II \\
\hline & 1 & Partial hip arthroplasty & II \\
\hline & 4 & Major abdominal surgery & II \\
\hline & 2 & Correction of $\mathrm{CHD}^{\mathrm{b}}$ in adult with $\mathrm{CPB}$ & । \\
\hline \multicolumn{4}{|l|}{ Other indications } \\
\hline $\mathrm{CN}$ in patient in sitting position & 2 & Access to posterior fossa tumor & II \\
\hline Heart surgery & 2 & Correction of $\mathrm{CHD}^{\mathrm{b}}$ in adult with $\mathrm{CPB}$ & I \\
\hline Total adult & 123 & & \\
\hline
\end{tabular}

a: abdominal aortic aneurysm; b: Congenital heart disease.

Table IV - Division of Groups According to TEE Intraoperative Usefulness

\begin{tabular}{llll}
\hline & Group 1 & Group 2 & Group 3 \\
\hline $\begin{array}{l}\text { Pediatric patients } \\
(41)\end{array}$ & $10(24.4 \%)$ & $27(65.8 \%)$ & $4(9.8 \%)$ \\
$\begin{array}{l}\text { Adult patients } \\
(123)\end{array}$ & $38(30.9 \%)$ & $81(65.9 \%)$ & $4(3.2 \%)$ \\
\hline
\end{tabular}

septal defect (ASD) to equalize left-right pressure returned to CPB to increase the ASD diameter. Third, one patient developed significant right ventricular dysfunction after closure of the sternum; so, we opted for maintaining the sternotomy until RV function improvement, which occurred on the second postoperative day when he returned to the operating room for closure of his chest. Fourth, a patient who underwent repair of the aortic valve return to CPB for valve reapproachment, since residual aortic insufficiency was quantified as moderate, which was considered unacceptable as a final result (Figure 3).

In 38 adult patients, TEE was useful only as a monitor. In 81 patients, it was important for hemodynamic management leading to the introduction and adjustment of vasoactive drugs or guiding volume replacement. In four patients, it directly in- terfered with surgical procedure. The first case was a patient referred to us for elective repair of a presumed pulmonary valve stenosis previously diagnosed by transthoracic echocardiography. In this patient, intraoperative examination showed a subaortic ventricular septal defect (VSD) with right ventricle outflow stenosis and normal pulmonary valve. The initial proposed surgical correction of stenosis was changed, and the surgery involved the VSD closure and infundibular widening (Figure 4). In the second case, an adult patient who underwent mitral valve repair returned to $\mathrm{CPB}$ immediately after the first attempt of weaning for surgical correction adjustment because the control TEE accused persistence of a moderate insufficiency after hemodynamic parameters normalization.

Considering only the cardiac surgery group in adults, a new information regarding the condition leading to surgery was added in $7.1 \%$ of cases, which lead to change in surgical approach in $3.5 \%$ of cases. In the last two cases, patients with pulmonary hypertension underwent the initial proposed colon surgery by video-laparoscopy. Immediately after pneumoperitoneum insufflation, both patients evolved with significant right ventricular distention and severe hemodynamic deterioration, which lead to conversion to conventional surgery.

In two cases, TEE was fundamental in detecting potentially life-threatening situations and allowed us to take quick decisions. In the first case, a patient with $\mathrm{PH}$ underwent total 


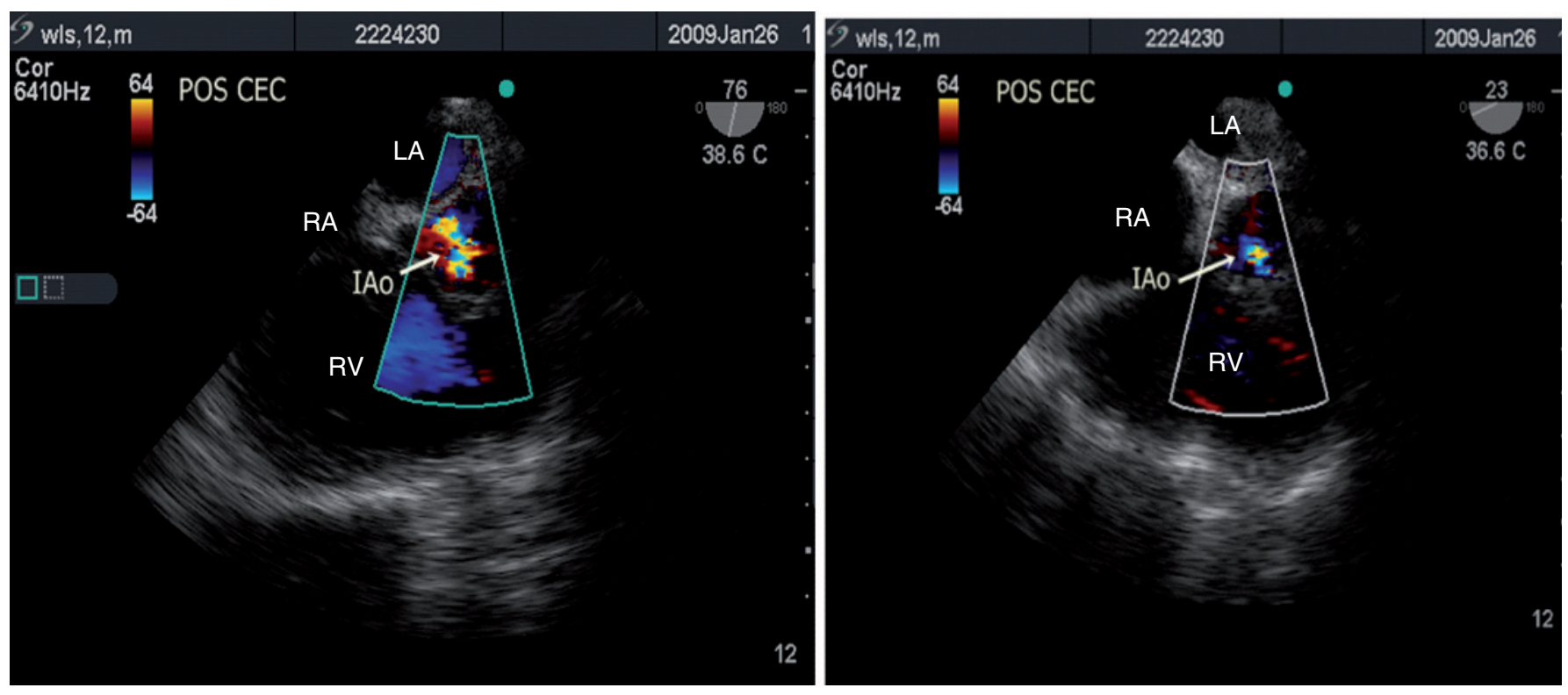

Figure 3 - Aortic Plan Short Axis with Multiplane Angle in $76^{\circ}$ (left) showing the result of control echo after the first attempt of repair, with residual aortic insufficiency quantified as moderate and the same plan (right) showing a mild aortic regurgitation as final result.

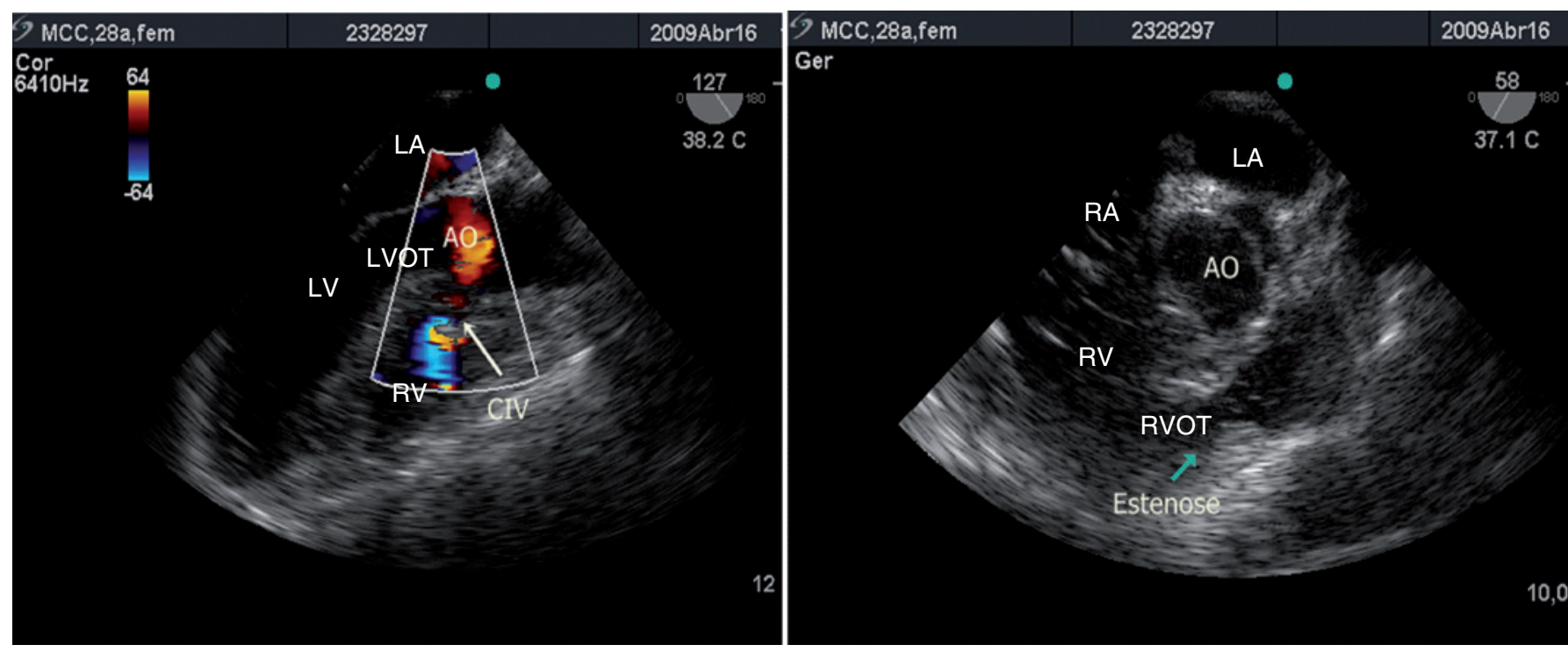

Figure 4 - Aortic Plan Long Axis (left) showing the subaorctic VSD and short axis plan (right) showing the right ventricular outflow tract (RVOT).

hip arthroplasty. At the end of femoral prosthesis component cement, she evolved with progressive increase in pulmonary pressure followed by cardiac arrest (CA). The differential diagnosis between the $\mathrm{PH}$ crisis and a possible pulmonary embolism (PE) could only be done because the pulmonary artery systolic pressure (PASP) assessment performed during monitoring showed the gradual increase of pressure, which reached a peak of $69 \mathrm{~mm} \mathrm{Hg}$. Resuscitation maneuvers were immediately initiated and, after restoration of spontaneous circulation, we chose the combination of nitric oxide with milrinone, which was already being administered from the onset, with excellent response. The patient was transferred to the in- tensive care unit and extubated 48 hours later, without neurological sequelae and evolving postoperatively without further complications. Below we have the assessment of PASP in two moments: before CA, reaching $69 \mathrm{~mm} \mathrm{Hg}$, and after clinical stabilization and installation of nitric oxide, now at lower levels (Figure 5).

The second situation with life-threatening potential occurred in a patient with a history of heart failure, coronary artery disease, and restricted to bed for two days due to a femoral neck fracture. She underwent a partial hip arthroplasty and after the procedure progressed to cardiac arrest. In this case, diagnostic suspicion arrived from the presence of McConnell' 


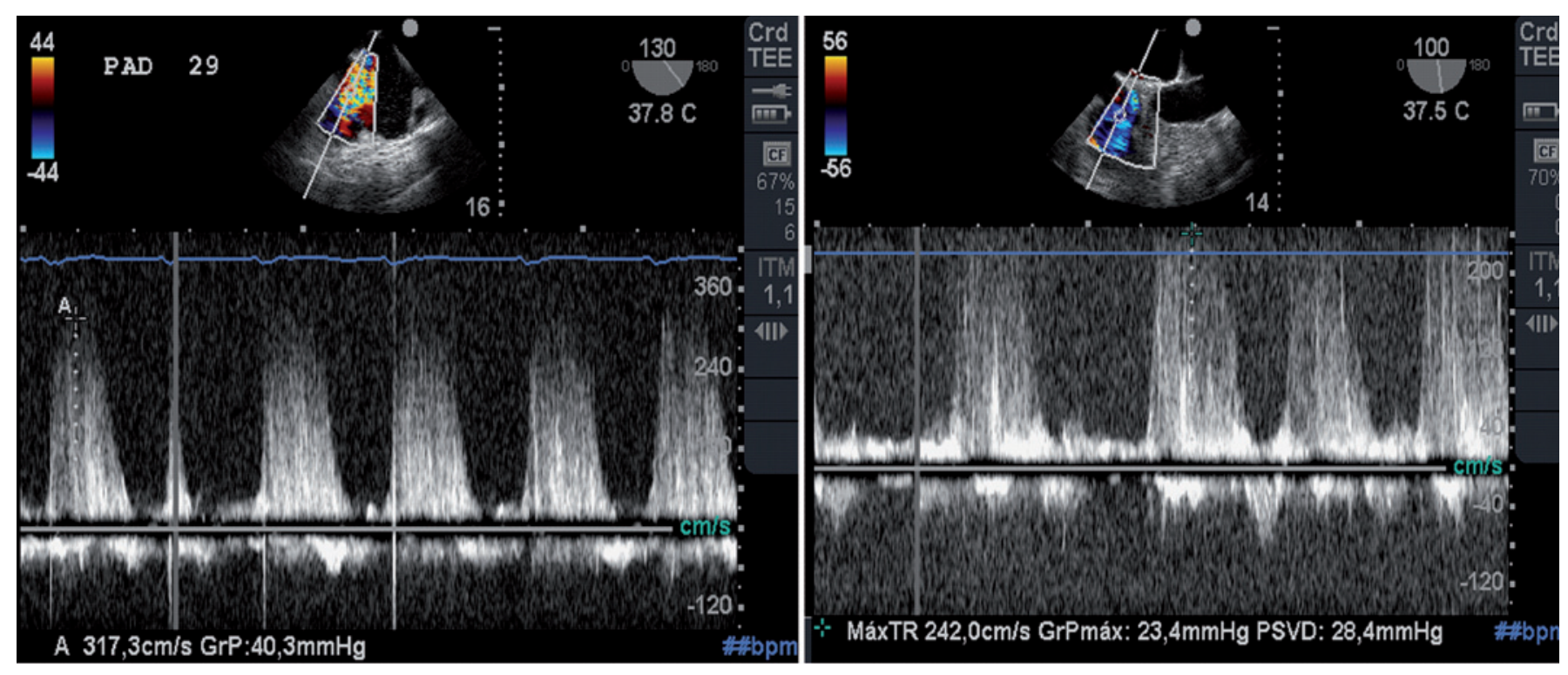

Figure 5 - PASP estimation (left) before CA at $69 \mathrm{mmHg}$ and after nitric oxide with lower value.

PASP: pulmonary artery systolic pressure; CA: cardiac arrest.

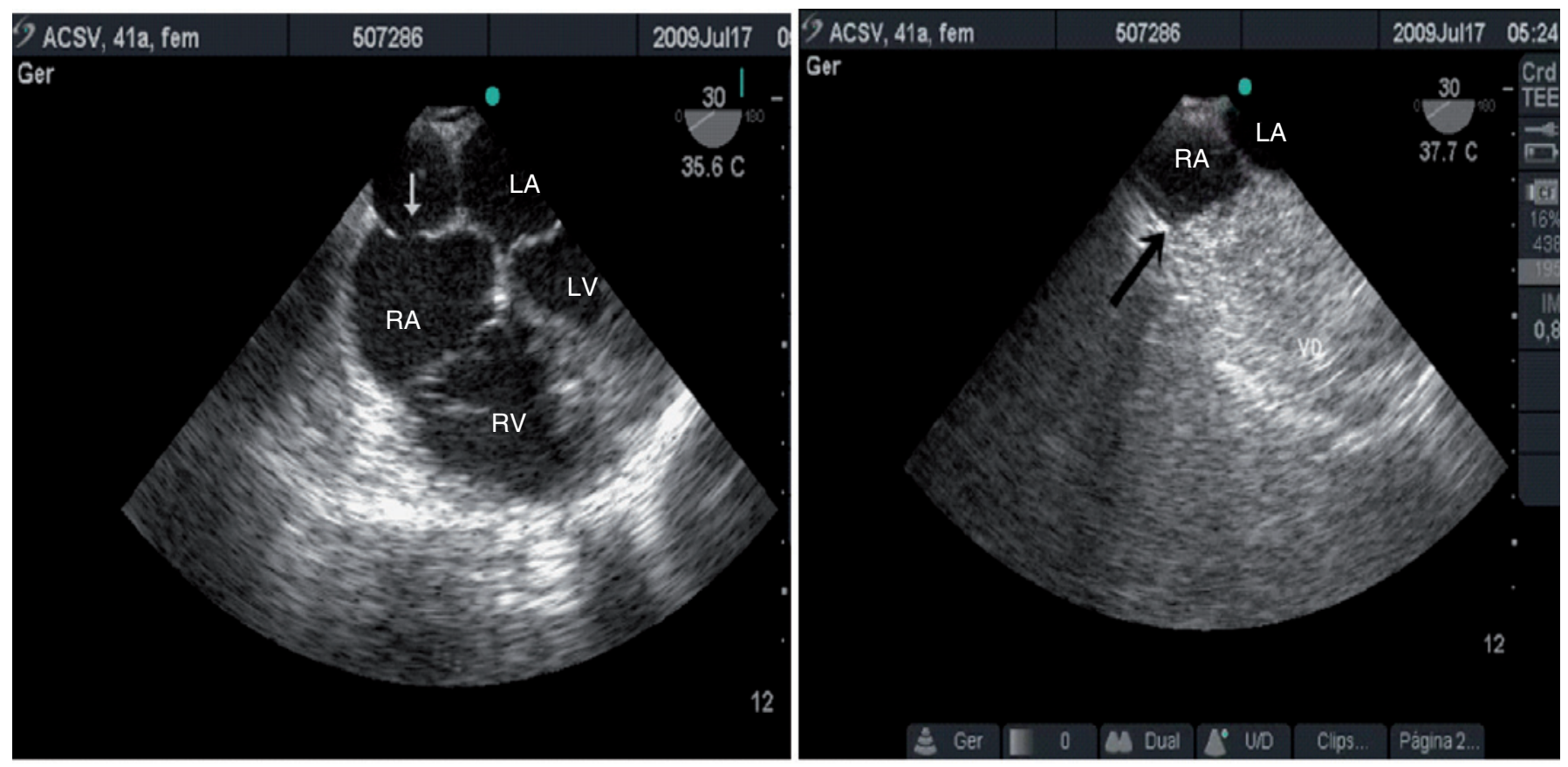

Figure 6A - Modified Four Chamber Cut Showing Right Atrium Divided by Elongated Eustachian Valve (white arrow).

Figure 6B - Functional Division View after Injection of Micro Bubbles Filling the Lower Portion of the Valve Limited by the Valve.

sign, which is an echocardiographic change characterized by abnormal contraction of the RV free wall, with normal contraction of its apex, and has a $77 \%$ sensitivity and $94 \%$ specificity for PE diagnosis. Due to the characteristic of CA and patient's critical situation, a new examination was requested on ICU arrival, and transthoracic echocardiography performed by specialist confirmed the TEE finding.

One of the diagnoses made during the intraoperative hemodynamic monitoring of a patient with heart failure, who underwent major abdominal surgery, was not involved in the proposed surgical procedure. The finding was a functional separation of the right atrium by an elongated Eustachian valve as shown in Figure 6.

The most challenging case in terms of monitoring was that of a patient who underwent lumbar laminectomy with spinal fusion the due to disabling pain. The indication in this case was unstable angina and, because of surgical positioning, TEE was performed throughout the procedure with the patient in the prone position (Figure 2). 


\section{DISCUSSION}

The first important aspect identified after the study was how important it is a standardized and organized record of all data for each examination, as it was through these records that we could easily get all data needed to perform the work. In addition, the digital storage of still images and films allowed us to resolve any doubts, either through review by our staff anesthetist or the opinion of an echocardiographer, if necessary.

Although our sample is small compared to those published outside Brazil, we found similarities between the results, which suggest great utility of TEE.

In pediatric patients undergoing heart surgery, our incidence of second CPB prompted by TEE was $7.3 \%$, which we consider not so far from the $8.5 \%$ reported by Bettex et al. ${ }^{11}$ in a retrospective of 10 years experience specifically using TEE in pediatric heart surgery. Other case series ${ }^{12,13}$ have reported up to $9.6 \%$ return to CPB prompted by TEE, which is also close to our results. The most important fact of our small case series is that after returning to CPB, in all three cases, significant surgical adjustment was required, which probably would need further surgery if they were not re-approached. In the patient whose chest was left open, in a subsequent analysis, the team thought this attitude was the most appropriate allowing the good outcome.

Regarding its use in adult heart surgery, the numbers are quite variable, and some published works have shown that intraoperative TEE may add new information regarding disease that prompted operation in $10 \%$ to $40 \%$ of cases and that this new information may result in change of surgical procedure in $4 \%$ to $15 \%$ of cases ${ }^{14,15,16}$. In our series, a new information regarding disease that prompted surgery was added in $7.1 \%$ of cases, which led to change in surgical procedure in $3.5 \%$ of cases. This difference may be explained by the small sample size of our study (28 patients), a number much lower than those reported in other studies ${ }^{17,18}$.

Similar to the study by Schulmeyer et al. 19, we also classify the usefulness of intraoperative TEE according to change in the information obtained from the echo, but we included only three groups in our study. Perhaps that was the reason why $65.9 \%$ of our patients were allocated to group II in which ETE motivated change in anesthetic approach versus $48 \%$ in the above mentioned study in which four groups were considered.

The use of TEE in noncardiac surgery is still controversial in literature and there are no large randomized, controlled, multicenter or meta-analysis studies confirming or completely denying its usefulness in this type of surgery.
Denault et al. ${ }^{20}$ published a paper showing that TEE was able to change the anesthetic-surgical procedure in up to $60 \%$ of cases in Class I patients, $31 \%$ in Class II, and in patients currently classified as Class III (i.e., those not eligible for intraoperative TEE), $21 \%$ had benefits and changes in the management of their cases. Similar results were obtained by other European studies that also associated the use of TEE with the same classification ${ }^{21,22}$. Among our patients, most were classified as Class II and almost all patients classified as Class I underwent heart surgery, which did not allow us to make comparisons with these data.

Another fact observed, also reported elsewhere, is that TEE is more likely to produce decisive changes in case management of patients with severe cardiovascular diseases undergoing noncardiac surgery. That became clear in cases of anesthesia in patients with pulmonary hypertension. In all cases, intraoperative TEE was essential regarding changes in management procedures.

In the patient undergoing total hip replacement, TEE has enabled us to gain a few precious seconds, recognizing the crisis of pulmonary hypertension, and eliminated the differential diagnosis of pulmonary embolism. This occurred in another case, also during an orthopedic surgery, and was recognized by the McConnell sign. In other patients, the change in the indication of video laparoscopy to conventional surgical technique was only possible because TEE also allowed the immediate diagnosis of acute right ventricular failure.

From this experience, we can also state that, although some information obtained depend on interpretation, most data that are important to the anesthesiologist comes from quantitative measurements performed on the basis of standardized procedures that can be easily reproduced by another examiner in case of uncertainty.

Similar to other technologies that have been incorporated into the operating room routine over time, we believe that very soon TEE will also be part of the hemodynamic monitoring arsenal of Brazilian hospitals that perform surgeries of high complexity.

Despite the small sample size and limitations of our study, the data suggest that TEE is an extremely useful tool for monitoring patients at risk, even when undergoing noncardiac surgery. Larger studies conducted in our country are needed, as there are no other studies in literature defining the use profile of TEE or even setting out clearly how it has been used in our field. 
2. Kolev N, Brase R, Swanevelder J et al. - European Perioperative TOE Research Group - The influence of transesophageal echocardiography on intraoperative decision making. A European multicentre study. Anaesthesia 53:767-773, 1998.

3. Morewood GH, Gallagher ME, Gaughan JP et al. - Current practice patterns for adult perioperative transesophageal echocardiography in the United States. Anesthesiology, 2001;95:1507-1512.

4. Ramamoorthy C, Lynn AM, Stevenson JG - Pro: Transesophageal echocardiography should be routinely used during pediatric open cardiac surgery. J Cardiothorac Vasc Anesth, 1999;13:629-631.

5. Qaddoura FE, Abel MD, Mecklenburg KL et al. - Role of intraoperative transesophageal echocardiography in patients having coronary artery bypass graft surgery. Ann Thorac Surg, 2004;78:1586-1590.

6. Hofer C, Zollinger A, Rak M et al. - Therapeutic impact of intraoperative transesophageal echocardiography during noncardiac surgery. Anaesthesia, 2004;59:3-9.

7. Suriani RJ, Neustein S, Shore-Lesserson L et al. - Intraoperative transesophageal echocardiography during noncardiac surgery. J Cardiothorac Vasc Anesth, 1998;12:274-280.

8. Shanewise J, Cheung A, Aronson S et al. - Practice guidelines for perioperative transesophageal echocardiography. Anesthesiology, 1996;84:986-1006.

9. Vieillard-Baron A, Chergui K, Rabiller A et al. - Superior vena caval collapsibility as a gauge of volume status in ventilated septic patients. Intensive Care Med, 2004;30(9):1734-9.

10. Feissel M, Michard F, Mangin I, Ruyer O, Faller JP, Teboul JL Respiratory changes in aortic blood velocity as an indicator of fluid responsiveness in ventilated patients with septic shock. Chest, 2001;119:867-873.

11. Bettex DA, Prêtre R, Jenni R, Schmid ER - Cost-Effectiveness of Routine Intraoperative Transesophageal Echocardiography in Pediatric Cardiac Surgery: A 10-Year Experience. Anesth Analg, 2005;100:1271-1275.

12. Stevenson JG - Adherence to physician training guidelines for pediatric transesophageal echocardiography affects the outcome of patients undergoing repair of congenital cardiac defects. J Am Soc Echocardiogr, 1999;12:165-172.

13. Roberson DA, Muhiudeen IA, Cahalan MK et al. - Intraoperative transesophageal echocardiography of ventricular septal defect. Echocardiography, 1991;8:687-697.

14. Jneid $H$, Bolli $R$ - Inotrope use at separation from cardiopulmonary bypass and the role of pre bypass TEE. J Cardiothorac Vasc Anesth, 2004;8:401-403.

15. Hillel Z - Refining intraoperative echocardiography. J Cardiothorac Vasc Anesth, 2003;17:419-421.

16. Thys DM - Echocardiography and anesthesiology successes and challenges. Anesthesiology, 2001;95:1313-1314.

17. Fanshawe M, Ellis C, Habib S, Konstadt SN, Reich DL - A Retrospective Analysis of the Costs and Benefits Related to Alterations in Cardiac Surgery from Routine Intraoperative Transesophageal Echocardiography. Anesth Analg, 2002;95:824-827.

18. Qaddoura FE, Abel MD, Mecklenburg KL et al. - Role of Intraoperative Transesophageal Echocardiography in Patients Having Coronary Artery Bypass Graft Surgery. Ann Thorac Surg, 2004;78:1586-1590.

19. Schulmeyer MCC, Santelices E, Vega R, Schmied S - Impact of Intraoperative Transesophageal Echocardiography During Noncardiac Surgery. J Cardioth Vasc Anest, 2006;20(6):768-771.

20. Denault A, Couture P, McKenty $S$ et al. - Perioperative use of transesophageal echocardiography by anesthesiologists: Impact in noncardiac surgery and in the intensive care unit. Can J Anesth, 2002;49:287-294

\section{REFERENCES}

1. Denault A, Couture P, McKenty S, et al. - Perioperative use of transesophageal echocardiography by anesthesiologists: Impact in non-cardiac surgery and in the intensive care unit. Can J Anasth, 2002;49:287-294.

21. Patteril M, Swaminathan M - Pro: Intraoperative transesophageal echocardiography is of utility in patients at high risk of adverse cardiac events undergoing noncardiac surgery. J Cardiothorac Vasc Anesth, 2004;18:107-109.

22. Miller JP, Lambert AS, Shapiro WA et al. - The adequacy of basic intraoperative transesophageal echocardiography performed by experienced anesthesiologists. Anesth Analg, 2001;92:1103-1110. 